\title{
Personal Librarian for Aboriginal Students: A Programmatic Assessment
}

\section{Jérôme Melançon and Nancy Goebel}

The Personal Librarian for Aboriginal Students (PLAS) program at the University of Alberta (UofA) is a creative outgrowth of the growing Personal Librarian programs in academic libraries, in which a student is partnered with an individual librarian for the academic year. In the case of the UofA's PLAS program, first-year undergraduate students who self-identified as Aboriginal during the registration process were selected as participants. The first year of the program saw many successes. This paper provides background on the initiative and the associated action research indicating a creative approach to engaging Aboriginal students.

\section{Introduction to Personal Librarian for Aboriginal Students (PLAS)}

There are many initiatives related to increasing the success and engagement of $\mathrm{Ab}$ original students at the University of Alberta campuses in the spirit of reconciliation as outlined in the report of the Truth and Reconciliation Commission. ${ }^{1}$ In response to the notion that undergraduate students often find the campus library and the research process intimidating, the PLAS program aims to address the way in which anxiety related to library use may act as a barrier to the success and engagement of Aboriginal students. ${ }^{2}$ Indeed, past interactions between the members of the program team and Aboriginal students have provided anecdotal evidence of library anxiety that was constant across students and across their interactions with team members, clearly echoing the findings in the limited literature on the needs of Indigenous peoples toward libraries. ${ }^{3}$ A program team was created to manage the operational and research aspects of the PLAS program. This program team consisted of a team lead (librarian), as well as non-librarian counterparts from teaching faculty and data systems and other individuals from a variety of university departments and committees whose mandate is to support Aboriginal students. PLAS was created in 2014-2015 and is a pilot program of the campuses of UofA.

As a sustainability measure, the PLAS program team determined that the participants in the PLAS program would be students who self-identified in the registration process as Aboriginal. The means by which PLAS sought to effect its goal of reducing anxiety among the Aboriginal student population was to assign a librarian to each

Jérôme Melançon is a Sessional Lecturer (Political Studies and Philosophy), Augustana Campus, University of Alberta, e-mail: jerome2@ualberta.ca; Nancy Goebel is the Head Librarian, Augustana Campus, University of Alberta, e-mail: nancy.goebel@ualberta.ca (c) 2016 Jérôme Melançon and Nancy Goebel, Attribution-NonCommercial 3.0 (http://creativecommons.org/licenses/by-nc/3.0/) CC BY-NC 3.0. 
student based on the discipline of the student's major. For each PLAS student, this librarian was the student's "Personal Librarian" (PL). First-year Aboriginal students who chose not to self-identify as Aboriginal during the registration process were advised of the option of registering for PLAS on the PLAS webpage. As all participants were first-year students, PLs were advised to follow their normal procedure by replying to inquiries outside of their subject expertise to the best of their ability or referring questions to subject librarians. This procedure acknowledges that first-year students take courses outside of their major and that librarians have expertise outside of their assigned subject area (especially at the lower levels). The advantage to the student is that they have a single person with whom they can be in touch for all inquiries. A program webpage (http://www.library.ualberta.ca/services/personal-librarian/) was created that provided background on the project as well as photos and contact information for each of the PLs.

The program team decided early in the project to use e-mail to communicate with the Aboriginal students. This was deemed an efficient way of reaching students and encouraging, ultimately, an in-person contact with the PL. It also provided the foundation for a program that would ultimately be scalable to other student populations when and if desired. Software called Industry Mailout (since renamed Mailout and available at https://mailout.com/) was used to send e-mails to students most weeks of the academic year. The e-mails contained short tips on how to do research or how to use a library resource or perhaps only a seasonal greeting. In all cases, the e-mails ended with the suggestion for the students to contact their PL. The contact information for the PL was provided in each e-mail.

\section{Framework and Methods: General}

In conceiving the PLAS program, the program librarian lead identified as its first challenge the need to reach and engage Aboriginal students. Indeed, to help students engage with libraries, librarians must first find ways to reach out to students beyond those who might use the libraries and seek help of their own accord. To meet this challenge, she assembled a program team that would be able to suggest practical ways of reaching students. Most of the members of this program team already worked with Aboriginal students and could participate both by speaking to students directly and by devising culturally appropriate and inviting ways of interacting with them. Other team members offered more specific contributions to the program, in terms of technical expertise in university information systems (required for downloading contact and program data for participating students), or in terms of ability to relate library use to teaching.

As a result of the composition of this program team, the PLAS program and associated research project took on three methodological axes: action research, Indigenous studies, and phenomenology. Action research was present as a matter of necessity, since the goals of the program and project included the creation of a capacity for assessment with the libraries, as well as increased engagement of Aboriginal students with the libraries. Indigenous perspectives were included: some program team members belong to Indigenous peoples, and others have learned about Indigenous peoples through their contact with students, continued learning, professional formation, or teaching and research. The project team also consulted the literature in Indigenous studies. Finally, a phenomenological approach underlay the development of the PLAS program and research project because of that approach's focus on the lived experiences of the individual and requirement that researchers begin any effort of understanding by suspending their belief in the validity of their cultural and institutional presuppositions about their own experiences and those of others. 


\section{Framework and Methods: The PLAS Program as an Action Research Program}

The needs of the program offered the program librarian lead the opportunity to develop processes adapted from those present in the literature on action research. Program team meetings followed the model of search conferences developed early in the history of action research by Trist. ${ }^{4}$ Trist, and $\mathrm{O}^{\prime}$ Brien who updated the process after him, suggest that researchers create a retreat or social island setting for such conferences, which aim to understand the problem for which research and action are needed, assembling stakeholders and isolating them for a period of time to allow them to focus on one aspect of their practice. In small groups, they gather the relevant information for understanding this aspect, envision the long-term outcomes they would like to see, and present hypotheses as to possible courses of action-all leading to decisions on the research that is to take place until the next search conference to inform further deliberation. However, it was neither possible nor necessary to create such a setting given the modest aims of the PLAS program as well as the fact that some members of the program team had already engaged in searching through their previous interactions with Aboriginal students; instead, the full program team met at semi-regular intervals throughout the academic year. These team meetings followed the model of search conferences in that the program team was composed of the relevant stakeholders (as described above) and their meetings included staff and faculty who could represent their coworkers who would interact with Aboriginal students in the context of their use of the library. These same staff and faculty members, as part of their daily activities, maintained contact with Aboriginal students involved in the program and were able to publicize and explain it and to relay the needs expressed by students.

The format of the search conference-or search meetings in our case-allowed a gradual and focused approach enabling those who deliver the services to be a part of their design and implementation. First, the program team discussed the general environment and attitude towards Aboriginal students at the university and in society, with the members providing all the information. Second, sub-groups were created to study issues previously defined and to which they could contribute directly, alleviating time constraints and using personal expertise. The program librarian lead was a member of all these teams and acted as a facilitator and as a link between groups. The sub-groups then reported to the program team and continued their work in this fashion until the program was underway. Third, the program team met periodically in each academic term to evaluate the progress and the limitations of the program, including at the end of the academic year, so as to evaluate the outcomes by discussing constraints, opportunities, and possibilities for the future. In this manner, the program team members used the model of the search conference not as a starting point for action research, but over time and in a manner that kept them engaged and responsive, and in keeping with the deliberative aspects central to the search conference.

Kitchen and Raynor suggest a set of premises for action research that resemble the objectives of the program team. ${ }^{5}$ The team's inquiry was aimed entirely at creating, maintaining, assessing, and re-creating a program that would transform the relationship between a selected student population and the library, having measurable effects on the student population as well as on the institution. ${ }^{6}$ As a result, the question "How do I improve my work?" was adapted to become "How do I better help Aboriginal students improve their work?" Data was gathered throughout the program, in the form of mailout.com reports regarding number of e-mails opened and links clicked and of accounts from PLs of their interactions with students. Research team reflections based on the evidence provided by this data followed, producing statements about the responses to the information sent to students; these statements led to future adjust- 
ments in the delivery of the PLAS program, and, once generalized, they ultimately led to recommendations to the library administration and informed this article.

Action research focuses on a democratic and participatory process, with the aim of pursuing knowledge and solutions in common, developing both the skills of the individual members of the program team and a sense of community among the group; ${ }^{7}$ in addition to these goals, and in keeping with their democratic aspects, the program team also sought to create equity for a specific population that tends to be excluded from university life and programs whenever its needs are not directly considered. In the context of PLAS, action research entailed decolonization and Indigenization of the UofA libraries. This process took place in three ways.

First, the PLAS program sought to decolonize the university by attempting to remove the barriers present as a result of settler colonialism, which for instance devalues Indigenous cultures and ways of knowing; blocks the possibility of pursuing Indigenous topics and interviewing Indigenous Elders; or presents the university and its libraries to Aboriginal students as sites that are foreign and unwelcoming, and which they experience as inaccessible and irrelevant. ${ }^{8}$ Within settler colonial states such as Canada, the United States, Australia, and New Zealand, education and Western knowledge were also used for colonialism, ${ }^{9}$ notably through residential schools, where education allowed knowledge, learning, and indeed everyday life to take place only in English (or French, as well, in Canada) and following a European model. There, Indigenous cultures were not only devalued but also forbidden.

Second, the PLAS program sought to take part in the Indigenization of the university by bringing key aspects of Indigenous ways of knowing and acting into the workings of the institution itself, as the latter applies to everyone. To do so, the program librarian lead ensured that training was provided for the PLs. Following the recommendation made by Roy that librarians be encouraged to read and learn about Indigenous peoples, ${ }^{10}$ PLs met with an Elder as part of their orientation. They also took part in a session on catalog subject headings, explaining the issues shown by Lee with the terminology about Indigenous peoples used in catalogs and in public life alike, with Eurocentric classification systems, and with the effects of the current organization of knowledge on the ways in which knowledge is created about Indigenous peoples. ${ }^{11}$ Being able to provide bibliographic information that is culturally relevant is a best practice in serving Indigenous students, ${ }^{12}$ and training and learning about Indigenous people also allows librarians, in their role within the PLAS program and in their other interactions with students, to be specific to the culture that is being researched; provide sources with accurate information; see Indigenous peoples as living in the present, not as belonging to history; and find sources that are free from bias. ${ }^{13}$

Third, beyond the training of PLs, the PLAS program sought to Indigenize the libraries by advertising their willingness to help Aboriginal students by developing their skills, and by encouraging them to share their enthusiasm about what they find. In doing so, the libraries recognized that as past interactions between the program team and students showed, many Indigenous students seek to find information about their culture and history once they arrive in university. Members of the program team mentioned that this desire emerges in part from having self-identified as Aboriginal. It also arises in part because the students do not have easy access to their culture and history, especially if they do not live on a reserve or are not from a reserve, as they will not have access to programs funded on reserve or to Elders, and as they will be far from tribal or cultural colleges. ${ }^{14}$

Students were engaged in the action research process from its inception to the implementation of the initiative. Aboriginal students had been consulted by team members prior to the creation of PLAS, which became a vehicle for addressing pre-existing 
concerns and commitments. As so many of the team members were selected because their job responsibilities had them interacting with Aboriginal students regularly, this allowed for continuous feedback without onerous time commitments on the part of students. As indicated below, students also provided programmatic feedback at the end of the academic year.

\section{Framework and Methods: The PLAS Program and Indigenous Education}

The PLAS program and research process were informed by scholarship related to Indigenous education, which respects lifelong learning and the diversity of holistic learning styles in learning about Indigenous and non-Indigenous subject matters and legitimizes the voice of Indigenous peoples by encouraging learning as a transformative experience in a community setting. ${ }^{15}$ This scholarship also undertakes a struggle for decolonization, which presents five dimensions: to realize that colonization continues and that something must be done about it; to reimagine the world on the basis of Indigenous knowledge; to bring different movements, public and scholarly, together to better understand the present and its possibilities; to disturb institutions as they are and seek change; and to understand the way in which Western hegemony structures society and quietly legitimizes and reproduces inequalities. ${ }^{16}$ Eliminating racism and notions of racial-cultural superiority, notably in the capacity for knowledge (cognitive imperialism) by valuing Indigenous ways of knowing and knowledge about Indigenous peoples, is also part of what Battiste calls an Indigenist research program. ${ }^{17}$

A PL program has the advantage of responding to the elements common to many Indigenous perspectives highlighted in the literature: developing relationships over time, embodying and modeling inclusion and generosity as values, respecting autonomy and self-determination in answering questions and solving problems. ${ }^{18}$ These elements are all related to "a preference for interpersonal interaction rather than interaction with automation or other inanimate entities"19 ${ }^{19}$ given that person-to-person relationships are more satisfying. Indeed, the imperative to build relationships is tied to the value of relationality, according to which reality is relationships, rather than merely formed by them, ${ }^{20}$ and that the purpose of research, as a ceremony, is to build stronger relationships. ${ }^{21}$

Expanding on these limited studies of the library needs of Indigenous students, the PLAS program focused on the development of relationships and personal connections with librarians and their effects on library anxiety. Lee observed in one study that the Indigenous students she interviewed almost all associated fear with their first experiences of the University of Alberta libraries - the exception being a student who had previous experience with university libraries - and that communication and relationship building with students would help alleviate their "intimidation and frustration." 22 However, she also notes that the six students interviewed were not aware of the service of one-on-one appointments with librarians, and this lack of awareness qualified their appreciation of librarians. They saw librarians as helpful and skilled, and as decisive in the quality of the students' overall experience, but also as lacking knowledge in their specific field, when compared to instructors.

\section{Framework and Methods: The PLAS Program and the Phenomenological Approach to Library Anxiety}

The co-researcher's method in assisting the program librarian lead in designing PLAS as a program and as a research project addressed the meaning of the experiences of library use in terms of relation to (1) physical spaces and materials, (2) other individuals (librarians and students in this space), and (3) the intellectual content of library materials and exchanges with staff. This method is phenomenological in that it took into 
account the primacy of face-to-face relationships in establishing all of students' other relationships. ${ }^{23}$ The experience of the libraries was thus addressed not only in terms of means and ends (e.g., writing a paper or helping a student to find sources) but also in terms of the desire to learn and succeed within the context of the university as an institution that underlies the process of library research, and in the context of students' own continuous attempt to reflect on who they are and to establish relationships with others. In doing so, the PLAS program addressed the two levels of intentionality analyzed by Merleau-Ponty: the goals that students give themselves consciously, and the existential aspects driving them, of which they are not usually aware. ${ }^{24}$

When considering the phenomenological approach to anxiety alongside the existing literature on library anxiety, ${ }^{25}$ the researchers found that library anxiety can be reduced to two major components: disorientation, and a more general sense of anxiety. Both of these feelings are the embodied experiences of students as they relate to the physical and virtual spaces of library collections, buildings, and e-resources, and to the people they find (or do not find) as they act within these spaces.

Students in their first year of study find that entering the new space of the library is disorienting, as they do not know what actions these spaces make possible or how to follow the directions they perceive in these spaces. Anxiety emerges from the choices that must be made in this space. Students do not need to access the library when resources are searched, selected, assembled, read, presented, or questioned for them by instructors. Without this support, they need to enter the physical or virtual space of the library, where they must make important decisions as to which authors and authorities to trust. This decision is the cause of both fear and excitement and demands a leap, a choice that is not dictated or obvious. Students then have a tendency to ignore guides and signs, not to complete their research. ${ }^{26}$ The result of experiencing anxiety tends to be to "satisfice" (to present their findings as "good enough") or giving up on the search. ${ }^{27}$

Librarians are able to reorient students by providing bearings and modeling behavior in the physical and virtual spaces of the library because they are present in a face-toface relationship with them. The PLAS program also brought the library to students, through technologies with which they are familiar, thus helping them overcome the mechanical barriers to accessing the libraries. ${ }^{28}$ In making librarians persons with names and faces, as well as specific functions and expertise, rather than mere contemporaries, the PLAS program also helped address the "barriers with staff," which are the most important dimension of library anxiety. ${ }^{29}$ Above all, librarians can show students that perfect sources do not exist and that uncertainty and anxiety are an intrinsic part of the research process. Librarians can help students productively use the feeling of anxiety to spur themselves on, on the basis of their confidence in their own skills and in those of the librarians, rather than to abandon their research too early. In the help they provide to students in relation to specific problems, librarians also participate in a transformation in the students' capacities.

The content of the e-mails sent to students was tied to these issues related to library anxiety. The e-mails sought to bring the library into students' lives by following the rhythm of the academic semester and year as they experienced it for the first time, as well as to show the relevance of the library and to reinforce the need and possibility to enter its spaces and use its collections at moments when reasons for doing so were likely to emerge. Some of the e-mails also directly addressed their emotions and the stress they were likely to experience at the end of the semester, advising of other library services such as quiet study spaces and pet therapy.

Two surveys were developed by the program team; one for students and one for PLs. They were administered through SurveyMonkey (analytics from SurveyMonkey were also used). In addition, the program team relied on the analytical statistics gener- 
ated from the Mailout software used to send content to students. PLs were given the opportunity for training and education on Aboriginal-themed issues throughout the year, in relation to the content of e-mails. On the basis of this methodology and general theoretical framework, the researchers analyzed the uptake of the PLAS program e-mails sent and analyzed the results of the surveys distributed to all participating students and PLs, combining qualitative and quantitative questions.

\section{Democracy of Study and Community of Inquiry}

There was intentionality with regard to the inclusion of a wide variety of perspectives in the PLAS program initiative. The PLAS program team members represented a variety of offices across the campuses that work closely with Aboriginal students in many capacities; some had already spoken with students in the past about their needs and anxiety toward the libraries. The program team's composition ensured that the views of students who interact with these staff members were considered throughout the program and that the program would emerge and develop based not only on the priorities of the university and libraries, but also on the demonstrated needs of students. The program team's composition also provided many opportunities for these staff members to share their accumulated wisdom. In addition, the PLAS program team was composed of a diverse group of individuals representing campus offices, genders, Aboriginal and non-Aboriginal populations, and staff position types.

The PLs were provided with a variety of educational opportunities that also gave the them the opportunity to ask questions related to the Association of College and Research Libraries' Assessment in Action initiative (which was the incentive for the creation of the PLAS program) and the PLAS program and to discuss any questions and provide feedback as a group. They discussed and explored stereotypes related to Indigenous peoples (e.g., a handout related to Indigenous peoples was created by the program team and distributed and discussed). In addition, library resources on Indigenous themes were identified, and each PL did a presentation to other PLs on a resource of choice. This was an efficient and effective manner in which to develop a stronger knowledge base on related library resources. A significant experience for the PLs was a meeting with an Aboriginal Elder for a conversation. This provided an opportunity to the PLs to ask any question because the Elder's role is educational so, just like in libraries, there are no questions too basic or obtuse to ask an Elder.

A community of inquiry was developed between the researchers and PLs, but also between the PLs and the students who consulted with them for specific assignments. In this manner, the PLs and the students were able to not only discuss and explore the narrow focus of the assignment but also explore together through conversation if they had specific needs as Aboriginal students. This approach, where PLs acted as a bridge between students and PLAS researchers, allowed for continued discussion and adaptation, based on PLs' relationship with students throughout the duration of the program and continuing throughout the subsequent research process. In this way the students' experiences and the PLs' interrogative processes informed the direction of the research and, operationally, of the PLAS program. The researchers' interactions with the PLs added to the library's assessment culture. The process was not perfect, and there are opportunities for learning and developing better communication practices.

\section{Findings}

The assessment of the PLAS program was based on the criteria set by the program team at the onset of the 2014-2015 academic year. As the program mainly took place through the dissemination of e-mails to pre-identified students, the first measure of 
success is the number of e-mails that were opened by students. Out of 19 e-mails sent to 179 students - a total of 3,155 individual e-mails - 1,847 were opened overall, for a rate of 58.6 percent of e-mails opened (the PLAS goal was an open rate of 50 percent). The mean for the number of times each student opened their e-mails was 10.5, which means that most students opened at least half of their e-mails.

The first eight e-mails had the largest uptake (between 134 and 104 openings of e-mails sent to 179 students). These e-mails focused on the basics of library research: greetings, PLs, finding sources, discovering the library, beginning research, feeling stressed, and avoiding fines. In comparison, e-mails in the second semester settled between 73 and 89 openings, with the least opened e-mail (by 66 students) focused on strategies for managing looming paper due dates. We can thus re-examine the success of the program by semester: 1,117 out of 1,696 e-mails in the fall semester (66 percent) indicates unexpected success, while 730 out of 1,459 e-mails (50 percent) indicates more modest success, but still in line with original expectations.

Received as an affirmation of the desire for services to be more personal, the e-mail opened the most was titled "Meet Your Personal Librarian" (134 openings, with the next e-mails standing at 119 openings). As another measure of the success of the program, only two of the 179 students included in the program at any point over the academic year opted to unsubscribe from the e-mail list, and only four of the 179 opened none of the e-mails.

The second measure of success is the number of embedded links on which students clicked after having opened the e-mails. While the criterion for success had been set at an average of 15 percent of all students clicking on any of the links in each e-mail, the results indicate that the use of links was unsuccessful: only 52 of the 179 students (29 percent) clicked on any links at all, and of them, only 5 students clicked on 4, 5, or 6 links throughout the year, while 30 of the 52 students clicked on one link. The mean number of students opening a URL in each e-mail was thus 4.05, far short of the 26 students that would represent 15 percent. The most popular links were "Meet Your Personal Librarian," "Avoid Those Nasty Fines," and "You Could Win a Bookstore Gift Card" for the survey $(9,14$, and 17 clicks respectively).

A phenomenological study of the experiences of students demands a holistic analysis, going beyond the tracking of their engagement with e-mails. Multidimensional measures provide the opportunity to understand how students' contact with the library, mediated through the reception and reading of e-mails and contact with PLs, affected their anxiety toward the libraries, their engagement with the libraries, and the interpretation they could give of the relationship between their use of the libraries and their participation in the PLAS program. Allowing students to establish connections between PLAS and their experiences has the advantage of helping them reflect on their experiences and on how they interact with the libraries, while using a survey allowed students to answer the questions at their convenience, during a busy time of the academic year.

As a result, we submitted a survey to the students at the end of the academic year through the same process as the regular PLAS program e-mails. Thirty-three students answered the survey, compared to the 52 who clicked on any of the links in the duration of the program and the 179 who received the e-mails announcing it. The researchers found that rate of participation satisfactory, as it matched other similar studies and as matters related to libraries are often not seen as a high priority by students. Rather than looking at each question in the survey, the assessment focuses on eight questions collectively acting as key indicators of the effect of the PLAS program on students' experiences, in relation to the number who have answered positively or negatively, and in comparison to our initial criteria (see table 1). 
TABLE 1

Answers to the Eight "Key Indicator" Questions on the Student Survey

\begin{tabular}{|c|c|c|c|c|c|}
\hline $\begin{array}{l}\text { Question } \\
\text { As a result of the Personal Librarian } \\
\text { program, have you visited the library } \\
\text { MORE OFTEN or LESS OFTEN than } \\
\text { you think you might have if you did not } \\
\text { participate in the program? }\end{array}$ & \multicolumn{4}{|c|}{ Responses } & $\begin{array}{l}\text { Criterion for success } \\
\mathbf{1 5 \%} \text { will report visiting the library } \\
\text { more often as a result of the PLAS } \\
\text { program. }\end{array}$ \\
\hline $\begin{array}{l}\text { As a result of the Personal Librarian } \\
\text { program, have you used the library's } \\
\text { collections (databases, articles, e-books, } \\
\text { paper books, library catalogue) MORE } \\
\text { OR LESS OFTEN than you think you } \\
\text { might have if you did not participate in the } \\
\text { program? }\end{array}$ & $\begin{array}{l}\text { More often: } \\
\text { 19/31 (63\%) }\end{array}$ & $\begin{array}{l}\text { About as often: } \\
9 / 31(30 \%)\end{array}$ & $\begin{array}{l}\text { Less often: } \\
0 / 31(0 \%)\end{array}$ & $\begin{array}{l}\text { Have not used } \\
\text { collections: } \\
\text { 2/31 (7\%) }\end{array}$ & $\begin{array}{l}\mathbf{2 5 \%} \text { of students will report and } \\
\text { increase the number of times and they } \\
\text { access library collections. }\end{array}$ \\
\hline $\begin{array}{l}\text { When searching for books or e-books } \\
\text { using the Library Catalogue, have you } \\
\text { used any of the tips or strategies you } \\
\text { learned as a result of your participation in } \\
\text { the Personal Librarian program? }\end{array}$ & $\begin{array}{c}\text { Yes: } \\
20 / 30(66 \%)\end{array}$ & $\begin{array}{c}\text { No: } \\
3 / 30(10 \%)\end{array}$ & $\begin{array}{l}\text { I have not used } \\
\text { the Library } \\
\text { Catalogue: } \\
7 / 30(33 \%)\end{array}$ & & $\begin{array}{l}\mathbf{2 5 \%} \text { of students will report that they } \\
\text { have used any of the tips or strategies } \\
\text { they learned as a result of their } \\
\text { participation in the PLAS program. }\end{array}$ \\
\hline $\begin{array}{l}\text { As a result of the Personal Librarian } \\
\text { program (including receiving e-mails), I } \\
\text { feel more comfortable asking library staff } \\
\text { for help. }\end{array}$ & $\begin{array}{c}\text { Strongly } \\
\text { Agree: } \\
16 / 29(55 \%)\end{array}$ & $\begin{array}{l}\text { Somewhat } \\
\text { agree: } \\
10 / 29(35 \%)\end{array}$ & $\begin{array}{l}\text { Somewhat } \\
\text { disagree: } \\
3 / 29(10 \%)\end{array}$ & $\begin{array}{l}\text { Disagree: } \\
\text { 0/29 (0\%) }\end{array}$ & $\begin{array}{l}\mathbf{5 0} \% \text { of students will report that PLAS } \\
\text { was a positive (defined as comfortable } \\
\text { and without anxiety), supportive } \\
\text { environment and student experience. }\end{array}$ \\
\hline $\begin{array}{l}\text { The Personal Librarian program positively } \\
\text { impacted my student experience. } \\
\text { NOTE: different measure from above for } \\
\text { same outcome. }\end{array}$ & $\begin{array}{c}\text { Yes: } \\
24 / 29(83 \%)\end{array}$ & $\begin{array}{c}\text { No: } \\
3 / 29(10 \%)\end{array}$ & $\begin{array}{c}\text { Other: } \\
2 / 29(7 \%)\end{array}$ & & $\begin{array}{l}\mathbf{5 0} \% \text { of students will report that PLAS } \\
\text { was a positive (defined as comfortable } \\
\text { and without anxiety), supportive } \\
\text { environment and student experience. }\end{array}$ \\
\hline $\begin{array}{l}\text { The Personal Librarian program positively } \\
\text { impacted my perspective of the library } \\
\text { as a comfortable and supportive place of } \\
\text { learning. }\end{array}$ & $\begin{array}{c}\text { Yes: } \\
\text { 23/29 (80\%) }\end{array}$ & $\begin{array}{c}\text { No: } \\
3 / 29(10 \%)\end{array}$ & $\begin{array}{c}\text { Other: } \\
3 / 29(10 \%)\end{array}$ & & $\begin{array}{l}\mathbf{5 0 \%} \text { of students will report that the } \\
\text { existence of PLAS impacts positively } \\
\text { the student's perspective of the library. }\end{array}$ \\
\hline
\end{tabular}


A third aspect of the program had to do with the possibility for students to research Indigenous themes and to use Indigenous ways of knowing, including citing Indigenous Elders (which is an important part of an oral tradition culture). It was on this aspect that the program achieved the least success. However, the researchers acknowledge that first-year students typically do very little library research and the goals were more about reducing student anxiety with the library and engaging them more than they might have otherwise been. When these students do research, they often have research topics that unrelated to Indigenous issues, either because of their vast interests or because they are not aware of the possibility to research Indigenous issues; and their instructors are often not aware or supportive of Indigenous ways of knowing. The program team has identified the opportunity to add to the e-mail related to citation the ability to cite Elders in undergraduate research.

A fourth and final aspect of the assessment addresses the participation of six librarians in the PLAS program. The most important impact was an increase of their awareness of issues Aboriginal students face in their undergraduate experience (for four of the six librarians, the other two indicating their awareness was already good), with this awareness mostly coming for the training provided to them, as well as through their interactions with students themselves (three out of six). As a result, the program was successful since it was meant for all librarians to have awareness. Other impacts included an increased awareness of Aboriginal collections and of searching techniques for these collections and an increased awareness of Aboriginal ways of knowing (although the awareness or understanding was for at least half the librarians only somewhat increased). Here the program was successful as well, with over half of the librarians reporting an increased understanding. Where the program may not have succeeded was in providing the opportunities to apply the skills developed through the PLAS program with other student populations (although the program did not seek to provide such opportunities, which may also be difficult to recognize, especially in the short term).

Properly assessing certain aspects of the program also proved to be quite difficult: we set the criteria for success of the program at a number of 10 percent of all students contacting their PLs; the students' survey indicates that 60 percent had, while librarians reported that 30 students (16 percent) contacted them. What is more, two librarians reported that they had not knowingly interacted with Aboriginal students. Without asking students to identify themselves to the PL as being part of the program and surveying a random sample of all students rather than self-selected students, it becomes impossible to assess the number of students who contacted PLs. Nonetheless, following the survey alone already indicates success, as 19 students indicated contact with a PL, which is a total of 10.5 percent of all students who participated in PLAS. What is more, on all other questions, results were always at least at twice the level indicated for success; however, it is difficult to know how many students were reached and engaged beyond those who responded. Numerous iterations of PLAS with increased student participation in assessment would provide the necessary data. A future option is to engage the student representatives on the various library committees as well as Aboriginal student representative from student associations in PLAS assessment.

\section{Conclusions, Decisions and Contributions}

Our conclusions are that, even counting for inflation in results due to the likelihood that the most active students in the PLAS program would also complete the survey, the program has, on each of the items above, achieved its goals. Students reported that the PLAS program led them to visit the library, to use its services, and to use them more effectively. In addition, it created a positive environment for their learning and research and demystified the library and lessened their anxiety toward it. In this manner, these 
aspects of the PLAS program contributed to the inclusion of self-identified Aboriginal students by establishing a closer relationship with librarians as well as the library and its services, facilities, and collections.

Based on the literature, we are also considering whether future iterations of the program might include more involvement of participating students in the research. While action research took place through a community of practice, it could be brought closer to community-based participatory research. In this manner, it could more closely follow the guidelines for Aboriginal research developed by the Social Sciences and Humanities Research Council of Canada, ${ }^{30}$ which involves a commitment to research being led not on or for Aboriginal peoples, but rather with them, as the researchers and program team have done, and as much as possible by them. What is more, following Jiao and Onwuegbuzie's recommendations, hiring Aboriginal staff in the library (even if through student positions) might also further alleviate student library anxiety and, if librarians, able to transform the libraries to make them more relevant. ${ }^{31}$

There are a number of ways in which the PLAS program contributed to the university as well as the university constituencies' understanding of the value of the library. These include:

- To the PLAS program team: Engagement in the process of action research as well as community building and a deepened awareness of the ways in which students can contribute to PLAS development.

- To the libraries: The educational opportunities given to PLs (including learning about library-based Aboriginal resources and meeting with Elders to discuss Aboriginal ways of knowing).

- To the university: Alignment with strategic directions to engage Aboriginal students on the campus and increase student success. It also is an opportunity to see the library as an active contributor to university initiatives.

- To students: Growth in familiarity with library services, collections, and facilities as mediated through the relationship with the PLs, as well as a more inclusive university experience and the creation of an intentionally inviting library environment and the establishment of connections themselves with librarians.

- To the Aboriginal communities: A better awareness of the needs of Aboriginal communities on the part of the library leadership and librarians.

- To other academic librarians: The PLAS program can be used as an example of a successful implementation of a Personal Librarian program.

- To other assessment practitioners: The opportunity to consider assessment through a mixed-methods (phenomenological and quantitative) approach.

Given the success of creating a new way to support the establishment of connections between first-year Aboriginal students and the library the PLAS team recommended to library administration that, based on the evidence drawn from the data, the PLAS program be expanded to other underrepresented first-year populations. Specifically, the recommendation includes international students and "academic at risk" students. This expansion creates an opportunity to apply what has been learned and to continue the learning and the advancement of a community of inquiry. A similar process will be undertaken to connect with campus partners who work with international students. In addition, defining what is understood as "academic at risk" will require working with a variety of campus offices such as the Registrar's office and Student Services.

\section{Notes}

1. The Truth and Reconciliation Commission of Canada was created in 2008 as part of a settlement agreement between the government of Canada and survivors of residential schools (akin to 
American Indian boarding schools). The commission's report, presented in June 2015, outlines 94 recommendations, many of which apply directly to universities or to the Canadian government's support of education for Aboriginal students and of the general public. The commissioners suggest that "Reconciliation must support Aboriginal peoples as they heal from the destructive legacies of colonization that have wreaked such havoc in their lives. But it must do even more. Reconciliation must inspire Aboriginal and non-Aboriginal peoples to transform Canadian society so that our children and grandchildren can live together in dignity, peace, and prosperity on these lands we now share." Truth and Reconciliation Commission of Canada, Honouring the Truth, Reconciling for the Future. Summary of the Final Report of the Truth and Reconciliation Commission of Canada (Ottawa: Truth and Reconciliation Commission of Canada, 2015), 8, http://www.trc.ca/websites/ trcinstitution/File/2015/Honouring_the_Truth_Reconciling_for_the_Future_July_23_2015.pdf.

2. This paper uses the terms Aboriginal and Indigenous in a non-interchangeable manner to describe students. Aboriginal has been the favored term in Canadian governments and universities since it was included in the Canadian Constitution to refer to First Nations, the Métis, and the Inuit. The term Indian, widely used in the United States to refer to "American Indians," is no longer used in Canada to refer to Canadian Aboriginals.

Equity programs have been created to recruit and retain Aboriginal students, who must then meet two criteria to be recognized as such: (1) they must self-identify as Aboriginal on their application form or later in their studies, and in some cases (2) they must provide proof of their Aboriginal status. "Aboriginal" students are then a specific administrative category defined for students, but not necessarily by them or their communities. However, since work began on the United Nations Declaration on the Rights of Indigenous Peoples, the term Indigenous has gained in popularity within groups otherwise designated as Aboriginal because it allows for more freedom in self-identification. As a result, a Cree or Métis student might self-identify as Aboriginal out of necessity to gain access to funding or more importantly to the services offered by the Aboriginal Student Services Centre (located on the North Campus in Edmonton) or the Aboriginal Students Office (located on the Augustana Campus in Camrose). However, outside of the UofA she might still prefer to present herself as Cree and as Indigenous. This paper thus refers to self-identified Aboriginal students, since it was the category used to select the participants in the program, and to Indigenous peoples and ways of knowing, as the social, cultural, and political counterpart to this student population.

3. Julien Kitchen and Marg Raynor, "Indigenizing Teacher Education: An Action Research Project," Canadian Journal of Action Research 14, no. 3 (2013): 40-58; Deborah A. Lee, "Aboriginal Students in Canada: A Case Study of Their Academic Information Needs and Library Use," Journal of Library Administration 33, no. 3-4 (2001): 259-92, doi:10.1300/J111v33n03_07; Deborah A. Lee, "Indigenous Knowledge Organization: A Study of Concepts, Terminology, Structure and (Mostly) Indigenous Voices," Partnership: The Canadian Journal of Library \& Information Practice \& Research 6, no. 1 (2011): 1-33; Deborah Lee and Deirdre Crichton, "Best Practices in Library Services for Aboriginal Peoples in Saskatchewan," in "Proceedings, World Library and Information Congress: 74th IFLA Conference General Conference and Council, 10-14 August 2008, Québec, Canada," 14 pages, http://archive.ifla.org/IV/ifla74/papers/118-Lee_Crichton-en.pdf; Frances D. Luther and Phyllis Lerat, "Using Digital Resources: Perceptions of First Nations University Students," School Libraries Worldwide 15, no. 1 (2009): 45-58.

4. Rory O'Brien, "Um exame da abordagem metodológica da pesquisa ação" ["An Overview of the Methodological Approach of Action Research"], in Teoria e Prática da Pesquisa Ação [Theory and Practice of Action Research], ed. Roberto Richardson (João Pessoa, Brazil: Universidade Federal da Paraíba, 2001), English version: http://www.web.ca/ robrien/papers/arfinal.html.

5. Kitchen and Raynor, "Indigenizing Teacher Education."

6. Morwenna Griffiths, "Action Research for/as/Mindful of Social Justice," in The SAGE Handbook of Educational Action Research, ed. Susan Noffke and Bridget Somek, 85-98 (Thousand Oaks, CA: SAGE, 2009).

7. Peter Reason and Hilary Bradbury, Handbook of Action Research (London: SAGE Publications, 2006), 1. See also the introductory essay to this issue of $C \mathcal{E} R L$.

8. Marie Ann Battiste, Decolonizing Education: Nourishing the Learning Spirit (Saskatoon, SK, Canada: Purich Publishing, 2013).

9. Linda T. Smith, Decolonizing Methodologies: Research and Indigenous Peoples, 2nd ed. (London: Zed Books, 2012).

10. Loriene Roy, "Recovering Native Identity: Developing Readers' Advisory Services for Non-Reservation Native Americans," Collection Building 12, no. 3-4 (1993): 73-77, doi:10.1108/ eb023347.

11. Lee, "Indigenous Knowledge Organization."

12. Lee and Crichton, "Best Practices in Library Services."

13. Roy, "Recovering Native Identity." 
14. Ibid. Reserves in Canada (called reservations in the United States) can exhibit a wide range of socioeconomic circumstances and means and have been, even recently, under close scrutiny by the federal government in the administration of their funds and programs - in those cases where they are given a modest amount of self-government, far from what they claim for themselves on the basis of the rights of nations to self-determination.

15. Battiste, Decolonizing Education; Smith, Decolonizing Methodologies; Shawn Wilson, Research Is Ceremony: Indigenous Research Methods (Halifax, NS, Canada: Fernwood Publishing, 2008).

16. Smith, Decolonizing Methodologies, 201.

17. Battiste, Decolonizing Education.

18. Lee, "Aboriginal Students in Canada"; Wilson, Research Is Ceremony.

19. Lee, "Aboriginal Students in Canada," 266.

20. Wilson, Research Is Ceremony, 7.

21. Ibid, 11.

22. Lee, "Aboriginal Students in Canada," 287.

23. Alfred Schütz, "The Dimensions of the Social World," in Collected Papers II: Studies in Social Theory, ed. Arvid Brodersen (The Hague, Netherlands: Martinus Nijhoff, 1976), 20-63.

24. Maurice Merleau-Ponty, Phenomenology of Perception (London: Routledge, 2002).

25. Sara Ahmed, The Cultural Politics of Emotions (London: Routledge, 2004); Sara Ahmed, Queer Phenomenology: Orientations, Objects, Others (London: Duke University Press, 2006); Michael J. Hyde, "The Experience of Anxiety: A Phenomenological Investigation," Quarterly Journal of Speech 66, no. 2 (1980): 140-54; Schütz, "Dimensions of the Social World"; Shelley Blundell and Frank Lambert, "Information Anxiety from the Undergraduate Student Perspective: A Pilot Study of Second Semester Freshmen," Journal of Education for Library and Information Science 55, no. 4 (2014): 261-73; Lesley J. Brown, "Trending Now-Reference Librarians: How Reference Librarians Work to Prevent Library Anxiety," Journal of Library Administration 51, no. 3 (2011): 309-17; Heather Carlile, "The Implications of Library Anxiety for Academic Reference Services: A Review of the Literature," Australian Academic \& Research Libraries 38, no. 2 (2007): 129-47; Gillian S. Gremmels, "Constance Mellon's 'Library Anxiety': An Appreciation and a Critique," College $\mathcal{E}$ Research Libraries 76, no. 3 (2015): 268-75; Constance Mellon, "Library Anxiety: A Grounded Theory and Its Development," College E Research Libraries 76, no. 3 (2015): 276-82; Shohreh Seyyed Hosseini, Abdolrasoul Khosravi, and Reza Basirian Jahromi, "Investigating the Relationship between Library Anxiety and Emotional Intelligence," Webology 11, no. 2 (2014): 13 pages, http:// www.webology.org/2014/v11n2/a129.pdf.

26. Hosseini, Khosravi, and Jahromi, "Investigating the Relationship," 2.

27. Blundell and Lambert, "Information Anxiety from the Undergraduate Student Perspective."

28. Hosseini, Khosravi, and Jahromi, "Investigating the Relationship," 10.

29. Brown, "Trending Now," 312.

30. Social Sciences and Humanities Research Council, "Aboriginal Research Statement of Principles," last modified June 3, 2015, http://www.sshrc-crsh.gc.ca/about-au_sujet/policies-politiques/ statements-enonces/aboriginal_research-recherche_autochtone-eng.aspx.

31. Alison Cleveland, "Library Anxiety: A Decade of Empirical Research," Library Review 53, no. 3 (2004): 177-85, doi:10.1108/00242530410526583. 